This pdf of your paper in Visualising the Neolithic belongs to the publishers Oxbow Books and it is their copyright.

As author you are licenced to make up to 50 offprints from it, but beyond that you may not publish it on the World Wide Web until three years from publication (October 2015), unless the site is a limited access intranet (password protected). If you have queries about this please contact the editorial department at Oxbow Books (editorial@oxbowbooks.com). 
Visualising the Neolithic 



\section{Visualising the Neolithic: Abstraction, Figuration, Performance, Representation}

Neolithic Studies Group Seminar Papers 13

\section{Edited by}

Andrew Cochrane and Andrew Meirion Jones

ISBN 978-1-84218-477-7

(C) Oxbow Books 2012 www.oxbowbooks.com 
This book is dedicated to the artist and photographer Ken Williams whose work is actively forwarding archaeological research and whose photographs embellish the cover of this book.

To view more of Ken's wonderful photography go to: www.shadowsandstone.com 
Foreword by Timothy Darvill and Kenneth Brophy ……………..................................................

List of Contributors ............................................................................................................... ix

1. Visualising the Neolithic: an introduction......................................................................... Andrew Cochrane and Andrew Meirion Jones

2. Strange swans and odd ducks: interpreting the ambiguous waterfowl imagery of Lake Onega. Antti Lahelma

3. 'Noble death': images of violence in the rock art of the White Sea 34 Liliana Janik

4. Reading between the grooves: regional variations in the style and deployment of 'cup and ring' marked stones across Britain and Ireland Kate Sharpe

5. Ben Lawers: carved rocks on a loud mountain 64 Richard Bradley and Aaron Watson

6. Living rocks: animacy, performance and the rock art of the Kilmartin region, Argyll, Scotland Andrew Meirion Jones

7. The halberd pillar at Ri Cruin cairn, Kilmartin, Argyll Stuart Needham and Trevor Cowie

8. Painting a picture of Neolithic Orkney: decorated stonework from the Ness of Brodgar.

Nick Card and Antonia Thomas

9. Inside and outside: visual culture at Loughcrew, Co Meath Elizabeth Shee Twohig

10. The figurative part of an abstract Neolithic iconography: hypotheses and directions of research in Irish and British Passage tomb art Guillaume Robin

11. Assuming the jigsaw had only one piece: abstraction, figuration and the interpretation of Irish Passage tomb art 161 Robert Hensey 
12. Composing the Neolithic at Knockroe

Andrew Cochrane

13. The circle, the cross and the limits of abstraction and figuration in north-western Iberian rock art

Lara Bacelar Alves

14. The Grimes Graves Goddess: an inscrutable smile

215 Gillian Varndell

15. The life and death of Linearbandkeramik figurines Daniela Hofmann

16. 'The 'no's' to the left have it!': sidedness and materiality of prehistoric artefacts

Bisserka Gaydarska

17. The shell, the pin and the earring: Balkan Copper Age mortuary costumes in context.

John Chapman

18. Trapped in postures

279 Stratos Nanoglou

19. Discussion: personality and Neolithic visual media 291 David Robinson 
Lara Bacelar Alves

larabacelar@sapo.pt

RichaRd BRADLEY

Department of Archaeology

University of Reading

Whiteknights

Reading, RG6 6AH

r.j.bradley@reading.ac.uk

NiCK CARD

Orkney Research Centre for Archaeology

Orkney College (UHI)

Kirkwall, KW15 1LX

nick.card@uhi.ac.uk

JoHn CHAPMAN

Durham University

Department of Archaeology

Durham, DH1 3LE

j.c.chapman@dur.ac.uk

ANDRew Cochrane

Sainsbury Institute for the Study of Japanese Arts and Cultures

64 The Close

Norwich, NR1 4DW

cochraneaj@gmail.com

Trevor Cowie

Department of Archaeology

National Museums Scotland

Chambers Street

Edinburgh, EH1 1JF

t.cowie@nms.ac.uk

Bisserka Gaydarska

Durham University

Department of Archaeology

Durham, DH1 3LE

b_gaydarska@yahoo.co.uk
Robert Hensey

Contact via: Dept. of Archaeology

School of Geography and Archaeology

NUI Galway, Co. Galway

http://independent.academia.edu/

RobertHensey

Daniela HofmanN

Cardiff University Centre for Lifelong

Learning

Senghennydd Road

Cardiff, CF24 4AG

HofmannD@cf.ac.uk

LiLIANA JANIK

Department of Archaeology

University of Cambridge

Downing Street

Cambridge, CB2 3DZ

lj102@cam.ac.uk

Andrew Merion Jones

Archaeology

Faculty of Humanities

University of Southampton

Highfield

Southampton, SO17 1BF

amj@soton.ac.uk

AntTi LAHELma

Department of Archaeology

University of Helsinki

Unioninkatu $38 \mathrm{~F}$

P.O Box 59

00014 Helsingin yliopisto

Finland

antti.lahelma@helsinki.fi 
Guillaume Robin

Università degli Studi di Sassari

Facoltà di Lettere e Filosofia

Piazza Conte di Moriana, 8

07100 Sassari

Italy

guillaume.robin@netcourrier.com

DAVID RoBINSON

School of Forensic \& Investigative Sciences

University of Central Lancashire

Preston, PR1 2HE

DWRobinson@uclan.ac.uk

Stratos Nanoglou

Stratos.Nanoglou@gmail.com

Stuart NeEdham

Langton Fold

South Harting,

West Sussex, GU31 5NW

sbowman1@waitrose.com

Kate E. Sharpe

Department of Archaeology

Durham University

South Road

Durham, DH1 3LE

kesharpe@live.co.uk
Antonia Thomas

Archaeology Department

University of the Highlands and Islands

Orkney College

East Road

Kirkwall, KW15 1LX

antonia.thomas@orkney.uhi.ac.uk

Elizabeth Twohig

Annestown

Co. Waterford

Ireland

etwohig@archaeology.ucc.ie

GiLLIAN VARNDELL

Deptartment of Prehistory and Europe

British Museum

Gt. Russell St.

London, WC1B 3DG

GVarndell@thebritishmuseum.ac.uk

AARON WATSON

www.monumental.uk.com

a.watson@monumental.uk.com 


\title{
Composing the Neolithic at Knockroe
}

\author{
Andrew Cochrane
}

This paper does not represent you. To be honest, it does not represent me either, so we already have something in common. What it does rather is present ideas that I have been working through for a while now. I am not expressing an anti-representational approach to Neolithic imagery - nor do I necessarily advocate that scholars adopt non-representational approaches verbatim. Instead, I traverse along paths that move beyond and are therefore more than representational understandings. The stimulus for such action derives from a recent sabbatical that I took away from passage tomb imagery. For the last two years I have been researching Jōmon dogū from the Japanese archipelago and prehistoric clay figurines from the Balkans (e.g. Bailey et al. 2010). I discovered that representational approaches to most archaeological enquiry occupied the dominant position. So implicit are representational understandings, that they often inhabit uncontested a priori assumptions. If we can no longer assume that anything can be assumed (Sloterdijk 2005; Shanks and Witmore 2009; Koerner 2010a) - why is this? What are the risks and implications of such a prevailing representational belief system within archaeology? What do we exclude when we focus on images as just being representational? Here, and via a case study of the passage tomb Knockroe, Co. Kilkenny, Ireland, I will explore what alternatives are available and demonstrate how these might work.

\section{BEING MORE THAN REPRESENTATIONAL}

'the representation of history. It requires a falsification of perspective'

W. G. Sebald

I think I understand why some people want to live in a world of symbols; it is after all comforting. To live without indices is destabilising - as Ronald Barthes (1970) and I (much later) discovered in Japan, through our inabilities to decipher the signs. This need or acceptance by some to read the world is manifest in some creations of Neolithic pasts and its imagery ${ }^{1}$ - and my concern is that this often appears to be done without overt qualification or reflection. In many ways, this situation reminds me of Alice's experiences in Wonderland - in which the Red Queen demanded the sentence first and the evidence after. Such positions are so dominant that even abstract geometric images are recast as being essentially representational and static - resulting in invisible transcendentals or first principles 
(Anderson and Harrison 2010, 14). Rendering the image depleted rather than pregnant (Lorimer 2005; Self 2006). It appears that no image can escape the modernist significances of representation and realism. ${ }^{2}$

Many expect one medium to replay what has already been given in another; the creation of original and copy - semblance and return (Doel 2010, 119). There is an idea that some archaeologists can discover a true or more correct world of realities lying behind a veil of appearances (Cochrane 2009a; Latour 2010). At a most honest level, however, images are sometimes just images. They can be stimulated by references to other images and they can be performative. Yet, they do not always just represent - in fact they can create situations whereby they only present with there being nothing behind them - often (to be playful?) they dissimulate that there is nothing to conceal (see Cochrane 2006). Within such approaches, the image is acknowledged to be sophisticated and autonomous enough to abolish prescribed referents and replace it with itself, creating a performance where the image is much more than applied representation. Here, the image is not passively awaiting overlays of meaning. Images are not about a thing - they are the thing.

\section{À REBOURS - AGAINST THE GRAIN}

Elsewhere, I have utilised select ethnographic accounts (e.g. Cochrane 2009a) to emphasis that not all recorded societies adopt representational approaches to the world, as is dominant in Western understandings (and Western accounts of non-Western people?). Thus far, alterity is not determined by how one (re)presents the world. Here, I will instead work with two vignettes of contemporary imagery as a means of discussing ways in which we can participate that is beyond mere representation, whilst opening up new and interesting questions ${ }^{3}$.

\section{VIGNETTE \#1}

As artists, The Chapman brothers (Jake and Dinos Chapman) explore scale and move through many of its spectrums. With many of their works there is no realism - their work does not represent - they include absurdities that defy realism and that do not allude to other meanings. Instead, their motivations are to stimulate and to be problematic. Contestation with reception can occur as some people are seeing what they think they see, rather than what is actually there. Interpretations for some are therefore based on illusion (or delusion), and a belief that the works represent things that are not present - meanings that are hidden - intangibles. Which the Chapmans explain is not the case - the works are what they are.

Some of their expressions deal in the diminutive; here, we have miniature-based sculptures of things that sometimes look like people within environments. The works Hell (1999-2000) - and Fucking Hell (2008) (remade after the original was ironically consumed by flames), produced thousands of miniature figurines, images, architectures and technologies within their own environments or 'hellscapes'. The dioramas can be interpreted as expressing some of the atrocities that some humans are capable of, such as genocide and mass destruction, but in the most inappropriate forms, with distortions of perception 
via medium and size. An important distinction in such interpretations is that the themed Nazis are not inflicting these horrors upon others, but rather themselves - they become the victims. These nightmarish acts are also administered to the Nazis by mutants and animals. If the figurines are to be interpreted as actual evil Nazis, the Chapmans argued that they thought people might be happy to see 10,000 of them being punished eternally for their sins in hell (Barrett and Head 2007, 5). Reception and opinion was, however, mixed with some people feeling that the figurines represented actual historical events (e.g., World War II and the Holocaust) or political statements (see Molyneux 1998). Indeed, at first glance the figurines can appear realistically accurate (e.g., the military uniforms). Yet on closer inspection, these works included absurdities that defy realism - incongruous things such as: a three-headed baby playing with a beach ball; Nazi astronauts; or an undead soldier riding a giant tortoise encouraging it forward with lettuce on a stick. Following Ingold (2007), we might be better by returning straight to the materials - this work is not human, it is a mixture of glass-fibre, plastic, and mixed media (in nine parts). The Chapmans explain that there are no hidden meanings - they have not added in this sense, but rather they are attempting to misplace (Barrett and Head 2007). These works are not analogies of something else - they are perfect models of themselves.

The Chapman works illustrate problems that face the study of prehistoric imagery and raises questions. For instance, what happens when we see motifs as having invisible or hidden analogies? Do the forms of motifs emulate other worlds, and is it useful to think in these terms? Can we consider Neolithic imagery as a reflection of realism? Are they created to be challenging and problematic? Is it more profitable to think about them for what they actually are or do?

\section{VIGNET'TE \#2}

Franz West is an artist who creates interactive art with the assertion that it does not matter what it looks like but how it is used (Fleck et al. 1999). Inspired initially by the avant-garde Actionists and literary groups in Vienna during the late 1960s, West eventually developed a fascination with the writings of Ludwig Wittgenstein (Badura-Triska 2006). West posited that performances are never fixed, but rather they change with the context of their application, only ever occurring within spaces of exchange. For West, art is meaningless and functionless unless it is interacted with - performance is key.

From the mid-1970s onwards, West began creating portable objects termed 'Adaptives' (Passtücke) - things that allow direct experiences beyond the mediation of language (Verwoert 2003). Varying in scale, but smaller than average human size, the Adaptives are found objects mixed with papier-mâché, wire, cloth bandages and plaster. The Adaptives are abstract and anamorphic shapes that can be held, manipulated, hugged or positioned in any manner chosen. They do not represent. The Adaptives sometimes look soothing and invite the handler to press them snugly into their body, and yet they almost always never fit - which can result in feelings of discomfort. These interactions with Adaptives often lead to the striking of amusing poses - destabilising the spectator and rendering them as performer - often facilitating a corporeal comedy (Storr 2003; Marcoci 2007). Here, activation is achieved by situations and by the objects inducing play. The objects percolate 
the uncanny, disrupt the quotidian, releasing tensions and previously unconsidered bodily gestures. As Ian Russell and I discovered in 2010 at the Hayward Gallery in London, the handler adapts to the object. These performances with objects are considered by West to be both liberating and acute reminders of existing repressions (Verwoert 2003). The Adaptive objects - as prosthesis - often create unease and site specific dislocations.

West argues that his objects present perspectives on how some people negotiate objects within the world. With the suggestion that Adaptives are prosthetic additions to the body, West attempts to blur modern distinctions that separate movement, human body, object and environment. West does not, however, communicate his ideas as text - it is usage and participation that articulate. That understanding and experience can be stimulated by physical contact and corporeal expression, presents challenges to how some archaeologists 'use' prehistoric material. West poses questions regarding not only the power of objects, but also the roles of play and performance in highlighting norms, and then subverting them. Following West, can we ever interpret the meaning of an object or image via notions of language and text alone? Or do we need to start handling and looking at them more and see what they do to us? How do seemingly functionless abstract objects and images work? At what point do the things we create stop adapting for us and when do we start adapting for them?

With these two modern examples and questions in mind I will now turn to the Neolithic.

\section{ÉLAN VITAL - KNOCKROE \\ 'a picture's beauty does not depend on the things portrayed in it' Marcel Proust}

Located near the modern village of Tullahought, Co. Kilkenny, Ireland, the Knockroe passage tomb, known also as the 'The Caiseal', is sited just above the $91 \mathrm{~m}$ contour on fields that fall to the west, above the bend in the Lingaun River, at the point where the east-flowing waterway fords and turns to the south, being 120m to the east of it (Ó Nualláin and Cody 1987, 69; O'Sullivan 1993b, 17; 2004, 46; see Figure 12.1). The positioning of this passage tomb differs from many others in Ireland (e.g. Newgrange Site 1, Co. Meath) in that it is placed on the side of the hill, rather than the highest elevated spot (O'Sullivan 1995, 11). The views are still impressive. Visible is the Baunfree tomb, located $4 \mathrm{~km}$ away on the northern edge of Kilmacoliver Hill, and the Slievenamon cairn approximately $11 \mathrm{~km}$ away on the mountain (Ó Nualláin and Cody 1987, 69). There is another cairn $1.1 \mathrm{~km}$ north-east of the Slievenamon cairn, but this is currently less prominent, due to its ruined condition. These sites may form a Slievenamon complex, similar in distribution pattern to the Boyne Valley and Loughcrew complexes in Co. Meath, albeit less compact (O'Sullivan 1993b, 15-16; 1995, 24), with Knockroe located towards the eastern end (O’Sullivan 2004, 44; see also Cooney 1990). The complex might also be associated to another scatter of monuments sited in the hills flanking the Aherlow River, a tributary entering the Suir River further to the west (O'Sullivan 2004, 44). The nearest decorated complex is Baltinglass Hill in Co. Wicklow, c. $60 \mathrm{~km}$ to the north-east (O'Sullivan 2004, 44). The geology of this area is Upper 
Silurian formations. The passage tomb was only brought to the attention of archaeologists very recently, when John Maher rediscovered the denuded remains in the very late twentieth century (Ó Nualláin and Cody 1987, 82; O’Sullivan 1993a, 33). This may have been as a result of it being recorded, but not shown, on the late nineteenth century and subsequent Ordnance Survey maps of Co. Kilkenny (Ó Nualláin and Cody 1987, 71). The structure consists of a semi-circular or elliptical kerbed earthen cairn (c. $15-25 \mathrm{~m}$ wide from east to west), with a small passage tomb on the western edge, and a second transeptal passage on the eastern side. In this respect it is remarkably similar to Knowth Site 1 and Dowth, Co. Meath, which also possess decorated motifs with two passage tombs within their mounds, and both are relatively close to waterways and smaller tombs (O'Sullivan 2004; Kondō 2001). It also highlights that the southern areas of Ireland, away from the Meath-Sligo axis, may not have been as bereft of megalithic motifs as was previously thought (O'Sullivan 1996a, 91; 2004, 44). The positioning of a single mound in a commanding position on a hilltop (albeit not the summit; see Figure 12.1) is similar to the Mound of the Hostages, Co. Meath and Knockmany, Co. Tyrone.

About 30 decorated stones are visible in the structural stones of Knockroe, with at least 10 of the kerbstones bearing motifs, 10 decorated stones in the western tomb and 10 in the eastern (O'Sullivan 1987, 92; 1996a, 91; 1996c, 11). Other than the main passage tombs in the Boyne Valley complex (e.g. Newgrange Site 1 and Knowth Site 1), this presents the

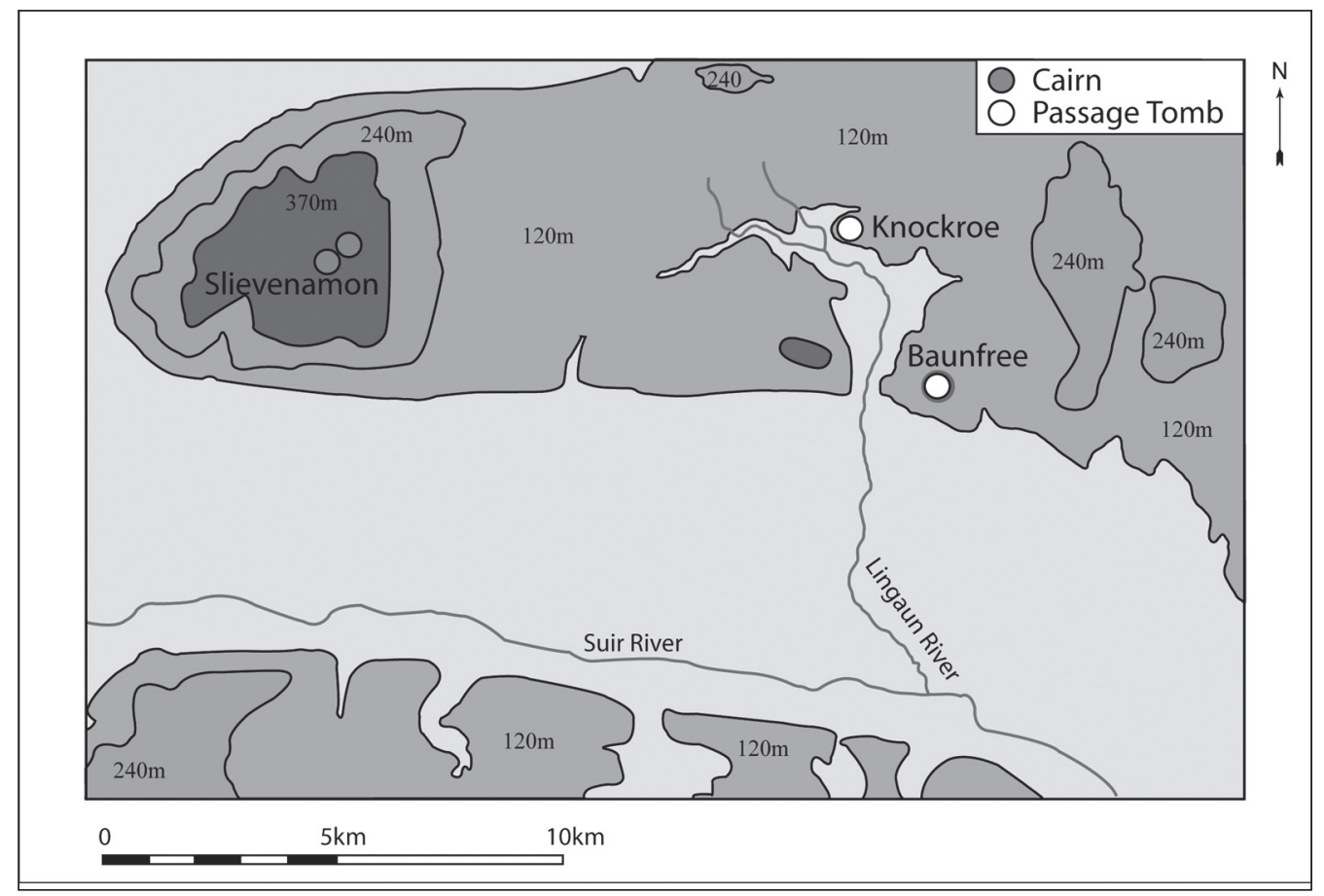

Figure 12.1: Schematic map showing the location of Knockroe and other sites within the Slievenamom complex (adapted from Ó Nuallain and Cody 1987, fig. 8). 
largest amount of decorated kerbstones in one particular monument (O'Sullivan 1987, 92; 1996a, 91; see Figure 12.2). I will highlight some of the more visually notable stones, to demonstrate the wealth of imagery present at Knockroe. Only eight of the kerbstones are thought to be in situ; four of these form pairs either side of the entrance to the western passage tomb, marking an in-turn into the entrance. The other four stones form an arc on the southern edge of the kerb (Ó Nualláin and Cody 1987, 73). The stones are mostly local sandstone, with green greywacke or grit bearing the majority of the imagery. This is argued to be a deliberate placement (O'Sullivan 1995, 12); green grit is also the favoured choice on some of the structural stones in the Boyne Valley passage tombs, such as Newgrange

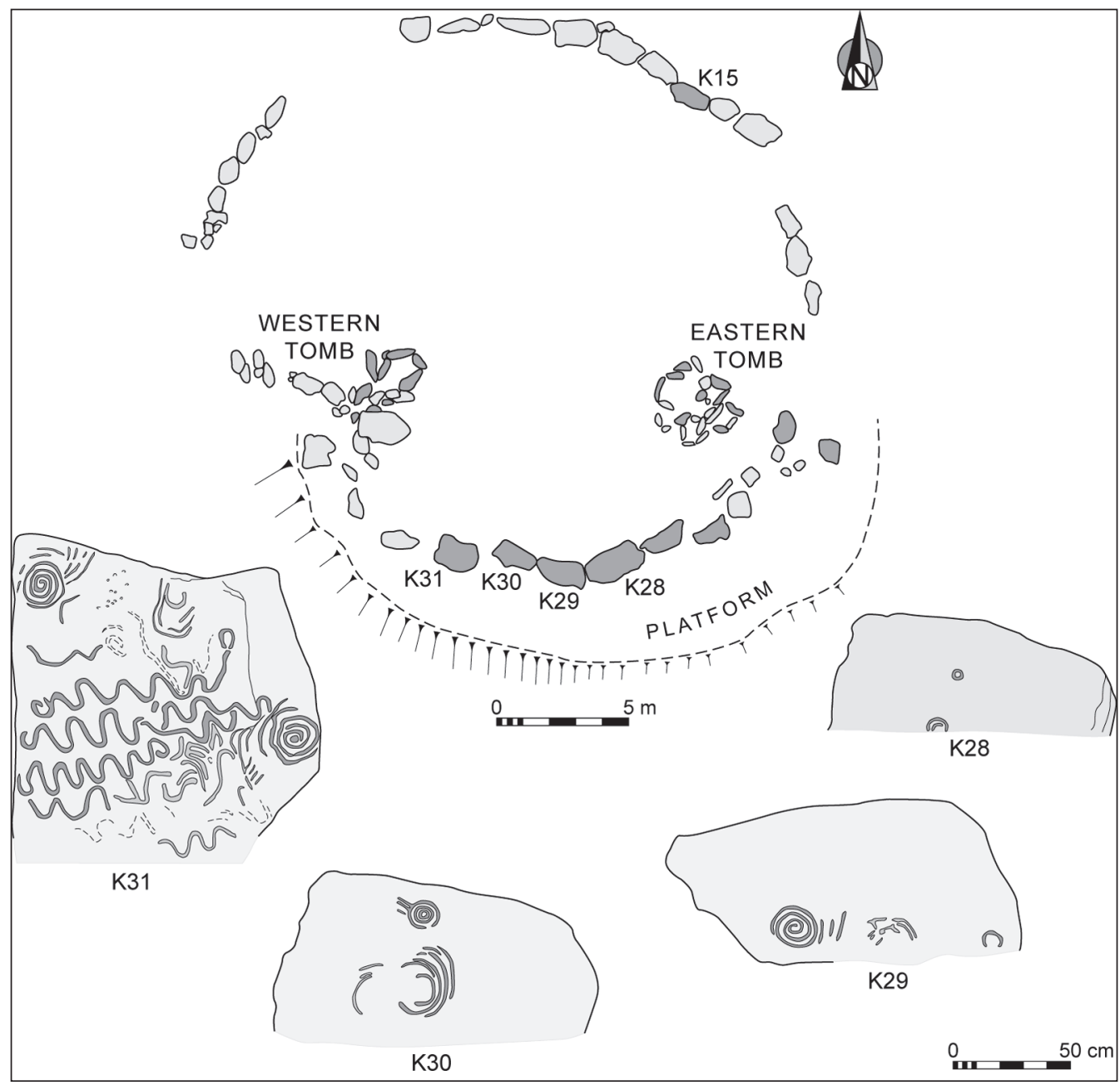

Figure 12.2: Plan of Knockroe passage tombs detailing some of the kerbstones discussed - shaded stones are decorated (adapted from Ó Nuallain and Cody 1987, fig. 9; O'Sullivan 1993b, 6; 1996c, 12; illustration by Aaron Watson). 
Site 1 and Dowth (Eogan 1986, 112). Ó Nualláin and Cody argue that the 'inconspicuous' $(1987,81)$ siting of this tomb on a slope was visually countered by the initial creation of a re-deposited yellow boulder clay platform, twice the diameter of the mound, which provided a level surface (see Figure 12.2). The extension of the earthen platform beyond the kerbstones could have also effectively created a stage (O'Sullivan 1996c, 13) for specific performances in front of both the western and eastern tombs, that may have allowed certain people to appear raised or above others. Such site specific performances may have been highly charged with emotions, with intoxicant fuelled carnal and sexual actions used as powerful tools to enhance experiences (see Cochrane 2005; 2008). Cacophony is not the right word - but it is one that springs to mind. The yellow boulder clay may also have been adapted for its impact (especially if illuminated by fire, moon or sunlight), for the feel and smell of it, and its contrast with the surrounding areas. Whether it stimulated such reactions or not, it does suggest that some people were actively altering the environment and being altered (or adapted) by it for different purposes (see also Cooney 2000a, 135). Interestingly, oval settings have been found directly in front of the entrances and façades of Cairn T Loughcrew, Knowth Site 1 and Newgrange Site 1, Co. Meath (Cochrane 2006a). Placed on this platform was a nodule of Galway granite; it is the only granite discovered at Knockroe and is reminiscent of granite placed at the entrances of Newgrange Site 1 and Knowth Site 1 (O'Sullivan 1997, 29). That Knockroe emerges out of the yellow clay and was constructed on top of it, rather than the clay merely being placed in front of it, may at some level indicate performances that invert or subvert worldviews. For instance, at Loughcrew, Co. Meath, I have previously discussed possible stage settings in between the passage tomb cairns (Cochrane 2005); at Knockroe the stage is now below and in front of the passage tombs, and possibly emphasises and allows alternative underlying engagements. The mixture of clay platforms, rock imagery and quartz is very reminiscent of Cairn T, Loughcrew where oval settings were cut into yellow clay, and contained a large quantity of white quartz fragments (Rotherham 1895, 311), and Torbhlaren, Argyll, Scotland, where quartz and clay is actively involved in the performance of image production and reception (see Jones this volume).

The western passage tomb consists of a widening passage (facing south-west) that leads to a terminal space that is only slightly larger at the inner end of the passage (Ó Nualláin and Cody 1987, 82; O’Sullivan 1993b, 5; see Figure 12.3). The passage tomb is compartmentalised into three sections, each entered over a sillstone and floored with a large stone slab (O'Sullivan 1996c, 12). This passage is $3.5 \mathrm{~m}$ long, $0.2 \mathrm{~m}$ wide at the entrance/exit and $c .1 \mathrm{~m}$ wide at the deepest end. As with Newgrange Site 1, the floor level rises in height from entrance to rear (O'Sullivan 1993b, 9; 1996c, 12). The passage tomb is aligned on the rising and setting sun on midwinter day, 21 December (O'Sullivan 1996a, 91; 2004, 47; see Figure 12.4). The structure consists of 12 orthostats, 5 on the southern side and 6 on the north side with one backstone. To the south of the entrance, $0.5 \mathrm{~m}$ away, is located a single stone $(0.6 \mathrm{~m}$ high) that may have presented an extension of the entrance beyond the line of the kerb (Ó Nualláin and Cody 1987, 73). The kerb appears to have been related to the western passage tomb, whereas the eastern passage tomb seems more detached and independent (O’Sullivan 1995, 12).

This extension beyond the kerb, combined with other stones, may have formed a sandstone block façade built upon the stage setting, creating a forecourt for possible 
activities to have taken place (Ó Nualláin and Cody 1987, 81; O’Sullivan 2004, 47). This extensive sandstone façade contrasts in colour and texture to the greywackes, and the stones do not contain imagery. This structural feature currently has no parallel (Ó Nualláin and Cody 1987, 73; O'Sullivan 1996c, 13; 2004, 47). The stage is also delineated by a broken line of flattish undecorated quartzite boulders that run adjacent to the earthen platform. That particular performances occurred here is supported by the discovery of a large pit cut into the platform, in-line with the passage tomb entrance (again similar to pits at the

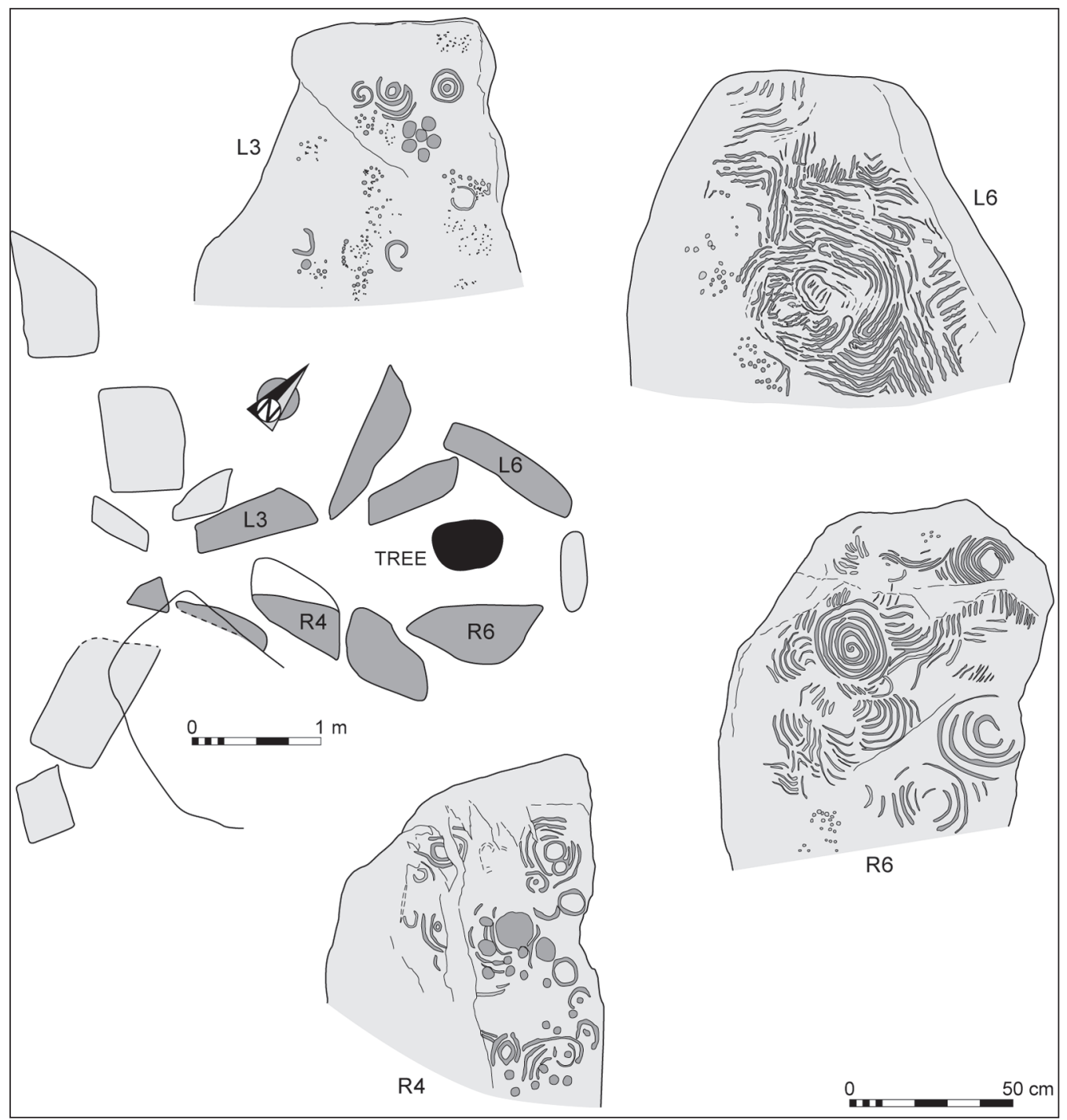

Figure 12.3: Plan of the western passage tomb - shaded stones are decorated (adapted from Ó Nuallain and Cody 1987, fig. 10; O'Sullivan 1987, figs. 15, 16, 17; illustration by Aaron Watson). 
Loughcrew and Boyne Valley complexes). The pit fill consisted of ash and baked soil, suggesting an intense or reoccurring fire(s) (O'Sullivan 1996c, 13). Just north of this feature another fire-pit was discovered; neither pit contained bone. Later activities on this platform include the placement of boulders (the largest being c. $1 \mathrm{~m}$ in length), in front of the passage tomb entrance (O’Sullivan 1996c, 13). These features may have been positioned to restrict movement in or out of the tomb, to stimulate bodily adaption, or they may have been used for some other purpose. Certainly, the blocking of the passage tomb sits well with Lynch's $(1973,152)$ communication proposal, although in this instance there is no aperture present (see also Sheridan 1985/6, 28). Here, we have active performances, rather than passive representation.

The heights of the kerbstones vary between $0.6 \mathrm{~m}$ and $1.3 \mathrm{~m}$. Most of the stones within this structure are green greywackes or grits and most are decorated. The exception is the unusually tall and oddly shaped undecorated pink sandstone located beside the sillstone at the entrance to the inner chamber (formerly known as Orthostat 9, western tomb) (O'Sullivan 1996a, 94). It is not local to the region and it is 'warped and asymmetrical' (O’Sullivan 2004, 48), being structurally 'illogical' (1996a, 94; 1996c, 12) - maybe performance was at play. Certainly, the visual and haptic aspects of this differently coloured and shaped stone and its ability to rupture the dynamics of the construction cannot be denied. The world is after all sensed and not just seen (Greenhough 2010, 43). Following the work of the Chapman brothers, this might be less about addition, and more about displacement. What we may be witnessing are subversive acts within the building process, with emphasis on the right hand side of the tomb. The priority of 'dexter over sinister' (Herity 1974, 123) is interestingly a feature of most passage tombs: evinced in the size of the right hand recesses; the motifs; artefacts and human remains (see also Robin 2010). Material discovered included 'mixtures of mixtures': cremated bone from several persons, some unburnt human and cattle bone, a mushroom-headed pin, a pendant and a bead (O'Sullivan 1996c, 12; see discussions in Cochrane 2007). Interestingly, a chevron decorated fragmented bone object (possibly a pin) was discovered - only three other similar examples are known in Ireland: two from Knowth Site 1 and one from Fourknocks I, Co, Meath (Eogan 1986, 143; O’Sullivan 2004, 49).

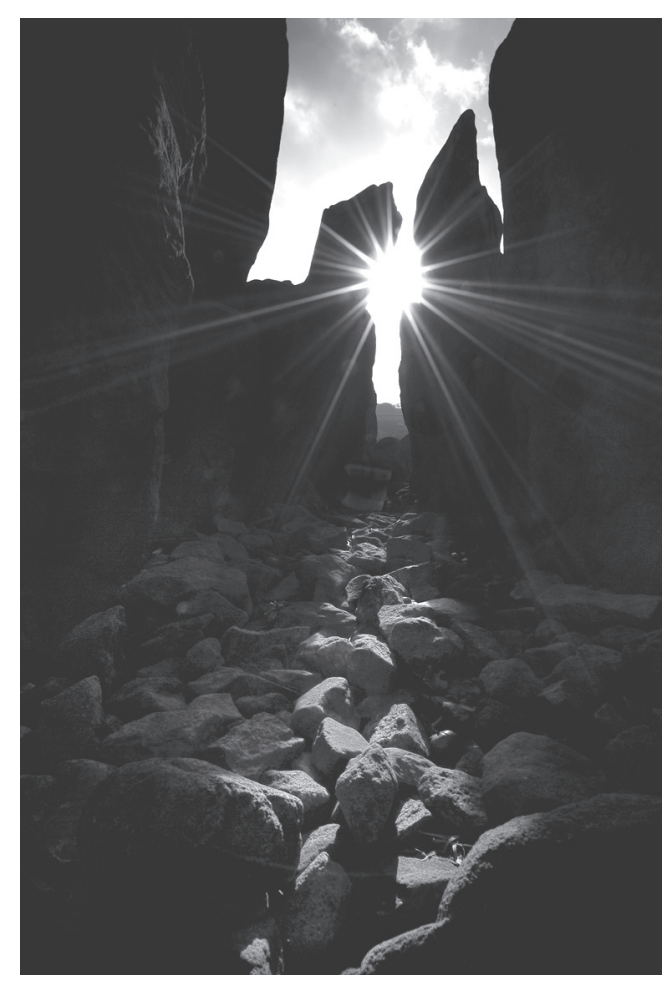

Figure 12.4: The winter late evening sun-setting in line with the western passage tomb (digital photograph: Ken Williams). 
There are 10 decorated stones within this passage tomb and they fit well within O'Sullivan's Stage 2 sequence (1996a), in that they are mostly basic geometric, yet with a coherent consideration to the modulations of the stone's surface - exploring the tensions. The carving on this tomb is bolder than that on the eastern one with the images themselves more extensively covering particular stones. In one instance, two opposing stones have mutually sympathetic/similar images. Creative movements of concern that affect through action (Anderson and Harrison 2010; Harris and Sørensen 2010). The substantive entrance to the passage here suggests that the structure remained open for longer periods of time than the eastern tomb, perhaps as a result of its particular solar alignment, and that successive performances occurred may explain why the motifs developed past Stage 1 images (O’Sullivan 1996a, 92). I will now briefly describe some of these decorated stones.

Located in the western passage tomb on the left-hand side of the chamber is Stone L3, which stands opposite Stone R4. The front face of Stone L3 is divided by an interrupted diagonal fissure/shelf (not humanly made) and contains extensive areas of loose picking and curvilinear motifs with cupmarks. The picking stops short of covering the entire surface - but creates impressions of generalisation, exaggeration and distortion. Concentric circles occur on the upper right of the stone and are 'delicately applied', with spiral forms nearby (O'Sullivan 1987, 84). Below these motifs are six cupmarks that are placed to produce a coherent looking shape, which suggests that they are deliberate. Stone L6 is located at the left hand inner end of the chamber as one enters it. The decoration occurs on the front face of this orthostat and is badly weathered and damaged, possibly from tree growth. The main design has been described as being integrated and structured around a curvilinear form in the centre, with radiating straight lines. Cupmarks are also present on the lower left segment of the stone (O'Sullivan 1987, 88). Next to this orthostat is positioned the backstone to the chamber at $0.95 \mathrm{~m}$ above the modern ground-level (O'Sullivan 1987, 88). The front face of this stone is flattish and smooth in texture, with imagery adorning it. The decoration is predominantly formed by zones of loose picking with some curvilinear shapes. The designs cover most of the front face of the stone but they do not reach the extreme edges. There is a single circle at the top of the stone in the middle and above this there is a penannular circle surrounding a cupmark. Interestingly, below the modern ground level is located a spiral (O’Sullivan 1987, 88). There are also patches of loose picking located on the back face of the stone.

Positioned adjacent to Stone L6, with similar imagery, is Stone R6. The motifs on this orthostat seem to respect the fissures in the stone, and therefore may conform to Stage 2 of O'Sullivan's (1996a) sequence. The middle face of the stone is dominated by a central spiral that is surrounded by radiating curvilinear arc shapes and parallel lines near the fissures. These tightly coiled linear designs are not found elsewhere in Ireland (O'Sullivan 2004, 49). Above and below the naturally demarcated band zone on the front face are located groups of concentric circles, and loose arc shapes (O'Sullivan 1987, 88). Experiencing the images here can create a visual stutter in the primary visual cortex, a moment of hesitation, stimulated by the saturation of imagery.

On the right of the main chamber is Stone R4. Although a large section of the front left hand face of this chamber has detached itself, it is still in situ. The dominant imagery on this stone consists of circles, loose concentric circles, cupmarks and radiating curvilinear lines that cover the front face and continue below the current ground level (O'Sullivan 
$1987,88)$. This feature may suggest that the orthostat was decorated before being placed in the passage tomb. Each new composition could have produced new experiences - not only the experience of touching it, or seeing it - but also in creating it. There does not have to be linear progression here - each fresh application is an encounter in it own right. Next to this orthostat, Stone R3 is located, near the entrance to the passage tomb. The documented imagery on this stone is currently very limited as most of the orthostat is still buried beneath the modern ground level. The visible motifs consist of a few curvilinear arcs, circles and a possible cupmark (O’Sullivan 1987, 88).

There are approximately six decorated kerbstones on the western passage tomb (Stones K26, K27, K28, K29, K30, K31; see also Figure 12.3). Stone K31 is extensively decorated, with imagery present over the entire front face. Motifs include large meandering lines that change from convex to concave and vice versa across the middle of the kerbstone, spirals that are diametrically opposed at an angle, and concentric circles (see Figure 12.5). Combined the motifs create a sense of modulated motion. There are also picking areas present on the left-hand side of the front face (O’Sullivan 1987, 88). Stones K30, K29, K28 and K27 are less dramatically decorated. The scope of the imagery is restricted to concentric arcs and circles, spirals and arcs. It is interesting to note that Stone K27 is possibly a green-grit, as is found in the Boyne Valley (O'Sullivan 1987, 90).

The eastern passage tomb is roughly aligned east-west, with a possibly transept-like feature on the north side, and is formed by a number of set stones that support large

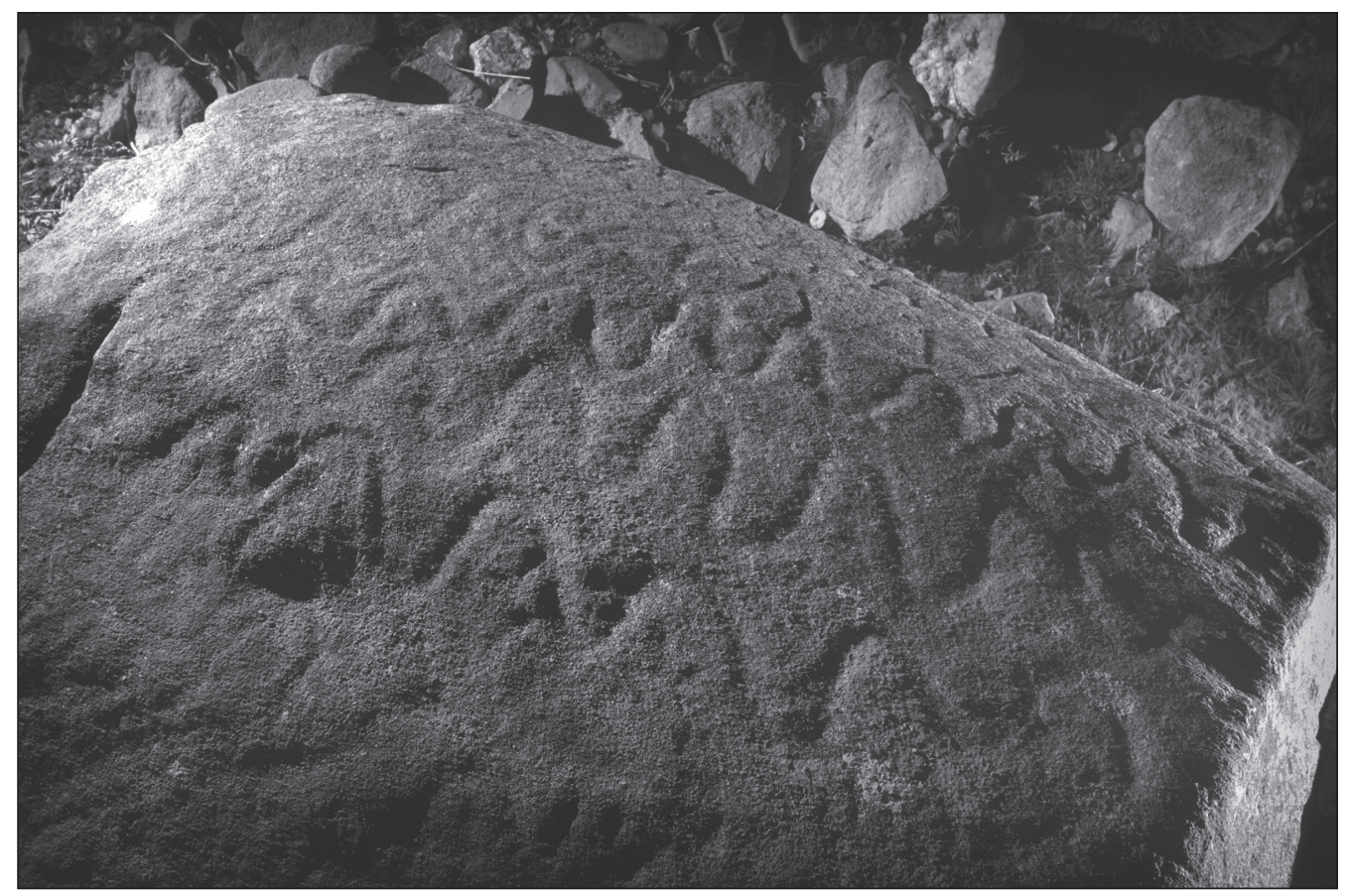

Figure 12.5: Stone K31, Knockroe (digital photograph: Ken Williams). 
slabs (six in total), with internal spatial divisions being indicated by sill stones. These compartments include outer, middle and inner sections, opposed lateral recesses and a cist-like structure (O'Sullivan 1995, 19; see Figure 12.6). The occurrence of a cist feature, filled with cremated human remains, is reminiscent of those found at the Mound of the Hostages, Tara, Co. Meath (O'Sullivan 2005; 2006). The passage tomb measures c. $3 \mathrm{~m}$ from entrance to rear and c. $2.3 \mathrm{~m}$ from side to side and probably had a corbelled roof (O'Sullivan 1995, 17; 20). There are two set stones on the southern end and four on the northern end,

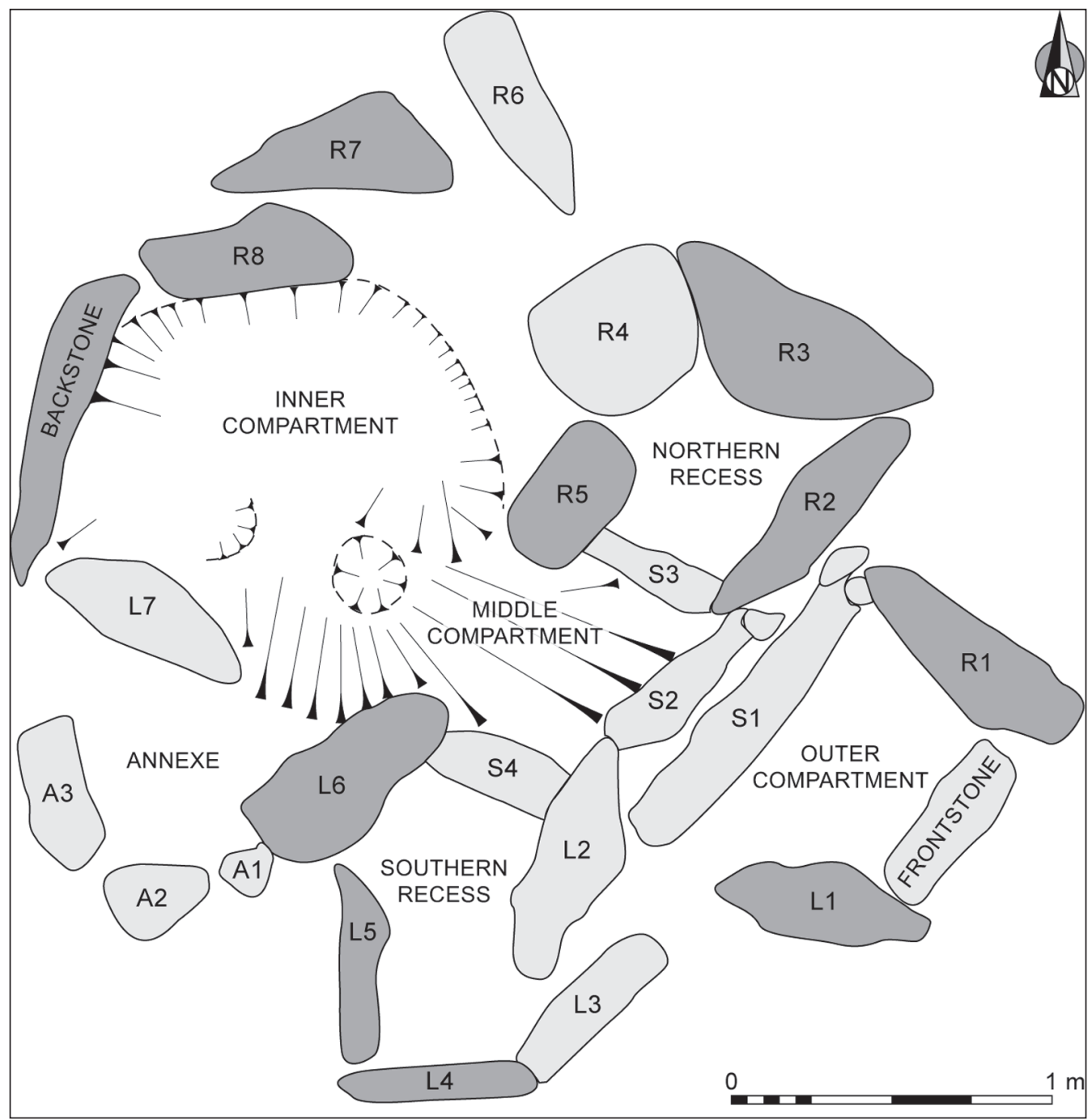

Figure 12.6: Knockroe East - shaded stones are decorated (adapted from O'Sullivan 1995, fig. 3; illustration by Aaron Watson). 
ranging in height between $0.13 \mathrm{~m}$ and $0.7 \mathrm{~m}$. The tomb in its current state is severely damaged (Ó Nualláin and Cody 1987, 82), with there being no evidence for an outer passage. The entrance is delineated by a transverse sandstone slab that is $c .0 .7 \mathrm{~m}$ high and flanked by Orthostats L1 and R1 (O'Sullivan 1995, 18). Located near this sandstone 'front-stone' was a similar shaped slab that may have rested above and acted as a temporary closing piece that could be swivelled sideways when admittance or exit was required (O'Sullivan 1995, 18). Access to this feature could have been granted via a puncture in the cairn, but only for a limited period of time (O'Sullivan 1996a, 91). Interestingly, scale is key to engagements with passage tombs - they can make one feel diminutive - and yet they can also make one feel large and awkward. Material discovered included more than $15 \mathrm{~kg}$ of cremated bone, mostly from within the tomb, Carrowkeel decorated red ware and undecorated flat-based pottery, bone pins, beads and a miniature macehead (O'Sullivan 1995, 23). The discovery of a Carrowkeel pot in situ mirrors the almost complete pots found in the Mound of the Hostages, Tara, suggesting that some pots were originally deposited intact, only fragmenting through later disturbances (O’Sullivan 1995, 26-7; Cochrane 2007). It is interesting to also note that the Carrowkeel pot was discovered in the right hand recess, near the backstone covered in natural hollows (O’Sullivan 1997, 26; 2004, 48). Here we have performances of articulation and disarticulation - composition and de-composition.

Three patches of burnt platform were also discovered in front of the eastern tomb (O'Sullivan 1993b, 14; 1996c, 13), and although they are not part of cut pits, they may be comparable to the fire-pits of the western passage tomb. Such fires may have been thought of as alive, being both gentle and comforting, but also unruly and dangerous, especially when roaring in the wind at night (Tringham 2005, 107). The fires would have enhanced sensational performances, with the colours of the flames and embers continually changing, accompanied by the sounds of cracking wood and stones, providing an ephemeral focus. The illuminating fire would have influenced the effects of the images enticing them to dance and move (Bradley 2010, 199). The smoke may have brought tears to the eyes, with the smell impregnating the hair and clothes. The heat itself from the fire may have warmed the skin and fuelled passions via the 'sexual excitement' that fire can bring (Tringham 2005, 107).

Although the eastern tomb has no formal passage, the kerb where an entrance area would have been was altered at some point in its life history, with the general greywacke or grit kerbstones being replaced with one conglomerate (K44) and four sandstones (e.g., K43 and K45) (O'Sullivan 1993b, 12). The eastern passage tomb also demonstrates some similarities with the Boyne Valley complex in that a quartz facing occurred above and in front of the sandstone kerbstones and stones mentioned above, with there also being water-rolled nodules on the ground in front of the entrance, and three sandstone balls (Ó Nualláin and Cody 1987, 73; O’Sullivan 1996a, 91; 1996c, 11; 2004, 48). This quartz layer has been interpreted as having slipped from the cairn sides in successive episodes, rather than being placed on the ground as is postulated as a possibility at Knowth Site 1, the eastern tomb (Eogan 1986, 45, 47, 65; O’Sullivan 1993b, 13). Quartz pieces were also discovered overlaying the primary deposits in the outer compartment, and this has been interpreted to have fallen in from overhead on the cairn (O'Sullivan 1995, 19). Within the fill of the annexe was located a large quartz block which may have originally been a roof-stone (O'Sullivan 1995, 21). There has been no attempt to describe a near-vertical quartz wall as is suggested for Newgrange Site 1 (O’Kelly 1982, 72, 110; cf. Bradley 1998, 101; Darvill 
2002, 82; Cooney 2006; 704; Eriksen 2006, 709; Stout and Stout 2008, 4-6). Associations with quartz and rock images are becoming increasingly complex, with evidences suggesting that quartz was also incorporated within performances of image production (e.g. Jones 2007; Jones et al. 2011; this volume).

Although no stone basin has been found in the eastern tomb, a large bowl shaped pit was discovered in the terminal chamber that may have served similar functions (O'Sullivan 1995, 21; for extend discussion see Cochrane 2007). Up to 10 structural stones are decorated, including Stones L1, L6, R1, R2, R3, R5, R7, R8 (O'Sullivan 1987, 90). All of the motifs in this passage tomb are badly weathered and can be described as belonging to O'Sullivan's Stage 1 , in that they are restricted to spirals, circles and ovals, with the plastic qualities seldom explored (O'Sullivan 1995, 15; 1996a, 91). The designs are lightly picked and small in scale, and in contrast to the western passage tomb appear less orientated towards a large scale visual impact and were possibly created in an earlier phase (see also O'Sullivan 1995, 25). Interestingly, the eastern tomb did not contain stone balls or mushroom-head pins, both of which normally form part of the passage tomb assemblages (O'Sullivan 1995, 26).

\section{INCITEMENT}

'One thing that literature would be greatly the better for

Would be a more restricted employment by the authors of simile and metaphor.'

Ogden Nash

With most passage tombs in Ireland there are similarities between their spatial contexts on topographically high locations, with the passage tomb mounds generally occupying positions long-ways on an east-west axis ridge (see also Herity 1974, 156; Cooney 1990, 743). That Knockroe locates itself in a visually commanding site within the side of a hilltop, might reflect an illusion or impression of centrality within the environment (see Watson 2004,88 ), allowing the site to be witnessed from lowland perspectives and vice versa. The physical effort involved in ascending the hill slopes, the politics of verticality, may have added to or influenced the experiences of the passage tomb. The compositions of the two passage tombs, platforms and mound may bespeak of emerging engagements within the broader environment (see also Bradley 1998, 100, 122-3). As such, Knockroe may have been responding to the hill upon which it resides, with the megalithic kerbs adapting to the mountains that frame the horizons. The initial condition of a place or chamber may have also allowed the creation of a conception place for performances, being 'bierophanies' (Eliade 1964, 32) or 'heterotopias' (Foucault 2002, 231-33; see discussions in Cochrane 2005); this would have possibly included the motifs and the placement of the dead. The noted interest in solar alignments might support this (see Hensey 2008). The usage of circular mounds and motifs may also have embodied different expressions of temporality that deny transformation as a forward striving force, instead being more about (dis)continuity and reduplicating reorganisations. Thus fostering experimental enactments - whilst encouraging flourishing forms (Rose 2010, 343). The motifs can be experienced as manipulations through stone (see Gormley 2004, 139), rendering presentations in rather than representations of the world. The repeated form of similar images may have served as acts to revitalise a particular integrity or sense of identity (see also O'Sullivan 2004, 49). It is the changes 
and stabilities that stimulate the fluid dialogues. The occurrence of quartz, the limited range of material remains (e.g. Carrowkeel ware, pins and stone balls), cremated remains, performances near the entrances and preferences for the right-hand side of the passage tomb may also support these propositions. The absence of stone basins is noteworthy. These locales, passage tombs and motifs move from merely occupying places of certainty in the world, and become the uncertain and provocative places of narrative and experience. If some people were attempting to perform a common world, it was something they were composing, building, fabricating and making together (Latour 2004, 455).

\section{BEING COMPOSED}

I have an idea for a new composition, which has no programme but will express what we understand by the spirit of life or manifestations of life, that is: everything that moves, that wants to live

Carl Nielsen

Nothing will ever be as good as you imagine it - significances, meanings, memories, (de)illusions to other worlds and entities - they are the intangibles - and they rarely wither. To move beyond these perennial occurrences has been one of the aims of this paper. Passage tombs were probably more sites of creation than curation - fluid rather than stable - adaptations in performance with folds with eddies (Cochrane 2006; 2010; Van Saaze 2009; Shanks and Witmore 2010). Motifs are therefore events in their own right and not subservient to an invisible immutable symbolic original - that is located just out there - or over there, or behind and below. Passage tomb images are an emergent novelty and a moment of uncertain hesitation with possibility.

\section{ACKNOWLEDGMENTS}

I would like to thank Alasdair Whittle and Douglass Bailey for commenting on very early drafts of this paper. Special thanks to Aaron Watson for creating the superb illustrations and for discussions, and also to Kate Waddington for helping create the map in Figure 12.1. The Knockroe photographs were created by Ken Williams - Ken's work never ceases to amazing me - the man is a legend! A big thank you to Muiris O'Sullivan for his support and for allowing me access to unpublished data on the Knockroe excavations (due out in 2012). Thank you to Simon Kaner for his support with this and other work. Andy Jones has big respect for his ongoing encouragement and for batting back critical comments - thank you! I dedicate this paper to James Marshall for his continual friendship.

\section{NOTES}

1 Such approaches have been dominant for over 150 years. They are representational and stipulate that things and meanings lie behind or just beyond the image - through the cracks if you like. They mostly subscribe to textual understandings - and often can be very expressionistic and poetic. Ultimately based on the idea that an image can represent something else - be it an ancestor, 
text, creature, hybrid, language, face, god, swastika, plant, celestial phenomenon, worldview or another image, like a hallucination. This sample list is by no means exhaustive: Wilde (1849); Deane (1889-91); Coffey (1912); Breuil (1921); Macalister (1921); Mahr (1937); Crawford (1957); Herity (1974); Brennan (1983); Thomas (1992); Lewis-Williams and Dowson (1993); Dronfield (1995); Tilley (1999); Nash (2002).

Within modernity it increasingly seems as if all images must represent. Supported by a long (a very long) history of archaeological assertion, I wonder how much more ink needs to be spent arguing that they can. In doing so, what would be the benefit to archaeology? At what point does it become cliché?

2 I am not proposing that we do away with representational understandings, as to do so would be to 'throw the baby out with the bath water' (Cochrane 2009a, 174). I have no wish either to replace the myth of representation with the 'myth of the clean slate', which demands negating all that went before and establishing a new order (Koerner 2010b). I also appreciate that categorisations of 'abstract' and 'geometric' are just conceits. As a beginning to a solution I suggest that we attempt to create a sense of conceptual equivalence in our interpretations (see also Introduction chapter in this volume).

3 As the Neolithic and contemporary art are both products of modernity, and only ever exist in the present, I feel that the creation of narratives with contemporary examples is perfectly appropriate (see Thomas 2004; Cochrane and Russell 2007; Renfrew 2003; Bradley 2009; Cochrane 2009b; Shanks and Witmore 2010; Russell 2011).

\section{REFERENCES}

Anderson, B. and Harrison, P. 2010. The promise of non-representational theories. In B. Anderson and P. Harrison (eds), Taking Place: non-representational theories and geography, 1-34. Farnham: Ashgate Publishing.

Badura-Triska, E. 2006. Franz West: early work. New York: David Zwirner.

Bailey, D., Cochrane, A. and Zambelli, J. 2010. unearthed: a comparative study of Jömon dogü and Neolitbic figurines. Norwich: SCVA.

Barrett, D. and Head, L. 2007. Jake and Dinos Chapman (New Art Up-Close 3). London: The Royal Jelly Factory.

Barthes, R. 1970 [2005]. Empire of Signs. Trans. R. Howard. London: Anchor Books.

Bradley, R. 1998 The Significance of Monuments: on the shaping of human experience in Neolithic and Bronze Europe. London: Routledge.

Bradley, R. 2010. Epilogue: drawing on stone. In J. Goldhahn, I. Fuglestvedt and A. Jones (eds), Changing Pictures: rock art traditions and visions in northern Europe, 197-205. Oxford: Oxbow Books.

Brennan, M. 1983. The Stars and the Stones: ancient art and astronomy in Ireland. London: Thames \& Hudson.

Breuil, H. 1921. Les pétroglyphes d’Irlande. Revue Archéologique 13, 75-8.

Cochrane, A. 2005. A taste of the unexpected: subverting mentalités through the motifs and settings of Irish passage tombs. In D. Hofmann, J. Mills and A. Cochrane (eds), Elements of Being: mentalités, identities and movement, 5-19. Oxford: British Archaeological Report 1437.

Cochrane, A. 2006. The simulacra and simulations of Irish Neolithic passage tombs. In I. Russell (ed.), Images, Representations and Heritage: moving beyond a modern approach to archaeology, 251-82. New York: Springer-Kluwer.

Cochrane, A. 2007. We have never been material. Journal of Iberian Archaeology 9/10, 138-57.

Cochrane, A. 2008. Some stimulating solutions. In C. Knappett and L. Malafouris (eds), Material Agency: towards a non-anthropocentric approach, 157-86. New York: Springer-Kluwer. 
Cochrane, A. 2009a. Additive subtraction: addressing pick-dressing in Irish passage tombs. In J. Thomas and V. Oliveira Jorge (eds), Archaeology and the Politics of Vision in a Post-modern Context, 163-85. Cambridge: Cambridge Scholars Publishing.

Cochrane, A. 2009b. What I think about when I think about Time. In J. Savage (ed.), Depending on Time, 30-4. Cardiff: Safle.

Cochrane, A. 2010. Re-playing the past in an age of mechanical reproduction. In S. Koerner and I. Russell (eds), The Unquiet Past, 33-47. Aldershot: Ashgate Publishing.

Cochrane, A. and Russell, I. 2007. Visualizing archaeologies: a manifesto. Cambridge Archaeological Journal 17(1), 3-19.

Coffey, G. 1912. New Grange and other Incised Tumuli in Ireland: the influence of Crete and the Aegean in the extreme west of Europe in early times. Dublin: Hodges, Figgis and Co.

Cooney, G. 1990. The place of megalithic tomb cemeteries in Ireland. Antiquity 64, 741-753.

Cooney, G. 2006. Newgrange - a view from the platform. Antiquity 80, 697-710.

Crawford, O. G. S. 1957. The Eye Goddess. London: Phoenix House.

Darvill, T. 2002. White on blonde: quartz pebbles and the use of quartz at Neolithic monuments in the Isle of Man and beyond. In A. Jones and G. Macgregor (eds.), Colouring the Past: the significance of colour in archaeological research, 73-91. Oxford: Berg.

Deane, T. N. 1889-91. On some ancient monuments scheduled under Sir John Lubbock's Act, 1882. Proccedings of the Royal Irish Academy 1 (Third Series), 161-5.

Doel, M. A. 2010. Representation and difference. In B. Anderson and P. Harrison (eds), Taking Place: non-representational theories and geography, 117-30. Farnham: Ashgate Publishing.

Dronfield, J. 1995. Subjective vision and the source of megalithic art. Antiquity 69, 539-49.

Eliade, M. 1964. Shamanism: archaic techniques of ecstasy. Princetown: Princetown University Press.

Eriksen, P. 2006. The rolling stones of Newgrange. Antiquity 80, 709-10.

Eogan, G. 1986 Knowth and the passage-tombs of Ireland. London: Thames \& Hudson.

Fleck, R., Curiger, B. and Benezra, N. 1999. Franz West. London: Phaidon Press.

Foucault, M. 2002. Of other spaces. Trans. J. Miskowiec. In N. Mirzoeff (ed.), The Visual Culture Reader: second edition, 229-36. London: Routledge.

Greenhough, B. 2010. Vitalist geographies: life and the more-than-human. In B. Anderson and P. Harrison (eds), Taking Place: non-representational theories and geography, 37-54. Farnham: Ashgate Publishing.

Gormley, A. 2004. Art as process. In C. Renfrew, C. Gosden and E. DeMarrais (eds), Substance, Memory, Display: archaeology and art, 131-51. Oxford: McDonald Institute for Archaeological Research.

Harris, O. and Sørensen, T. F. 2010. Rethinking emotion and material culture. Archaeological Dialogues 17(2) 145-63.

Hensey, R. 2008. The observance of light: a ritualistic perspective on 'imperfectly' aligned passage tombs. Time and Mind 1(3), 319-29.

Herity, M. 1974. Irish Passage Graves: Neolithic tomb-builders in Ireland and Britain, 2500 BC. Dublin: Irish University Press.

Jones, A. 2007. Excavating art: recent excavations at the rock art sites at Torbhlaren, near Kilmartin, mid-Argyll, Scotland. Past 57, 1-3.

Jones, A., Freedman, D., Lamdin-Whymark, H., O’Connor, B., Tipping, R. and Watson, A. 2011. An Animate Landscape: rock art and the prehistory of Kilmartin, Argyll. Oxford: Windgather Press.

Koerner, S. 2010a. Preface: 'Playing Statues'. In S. Koerner and I. Russell (eds), The Unquiet Past, xiii-xv. Aldershot: Ashgate Publishing.

Koerner, S. 2010b. rethinking 'crises over representation'. In S. Koerner and I. Russell (eds), The Unquiet Past, 1-7. Aldershot: Ashgate Publishing.

Kondō, Y. 2011. Passage Grave Cemeteries of Ireland: focusing on Loughcrew. Kyoto: Shin'yosha Co.

Latour, B. 2004. Whose cosmos? Which cosmopolitics? Common Knowledge 10(3), 450-62. 
Latour, B. 2010. An attempt at a 'Compositionist Manifesto'. New Literary History 41, 471-90.

Lewis-Williams, J. D. and Dowson, T. A. 1993. On vision and power in the Neolithic: evidence from the decorated monuments. Current Anthropology 34(1), 55-65.

Lorimer, H. 2005. Cultural geography: the busyness of being 'more-than-representational'. Progress in Human Geography 29(1), 83-94.

Macalister, R. A. S. 1921. Ireland in pre-Celtic Times. Dublin.

Mahr, A. 1937. New prospects and problems in Irish prehistory: presidential address for 1937. Proceedings of the Prehistoric Society 3, 201-436.

Marcoci, R. 2007. Interview with Franz West. In R, Marcoci (ed.), Comic Abstraction: image-breaking, image-making, 114-19. New York: The Museum of Modern Art.

Molyneux, J. 1998. State of the art: a review of the 'Sensation' exhibition at the Royal Academy of Arts, September-December 1997. INTERNATIONAL SOCLALISM 79. Available at: http:// pubs.socialistreviewindex.org.uk/isj79/molyneux.htm Accessed: 15 December 2009.

Nash, G. 2002. The landscape brought within: a re-evaluation of the rock-painting site at Tumlehed, Torslanda, Göteborg, west Sweden. In G. Nash and C. Chippindale (eds), European Landscapes of Rock-art, 176-94. London: Routledge.

O'Sullivan, M. 1986. Approaches to passage tomb art. Journal of the Royal Society of Antiquaries of Ireland 116, 68-83.

O'Sullivan, M. 1987. The art of the passage tomb at Knockroe, county Kilkenny. of the Royal Society of Antiquaries of Ireland 117, 84-95.

O'Sullivan, M. 1989. A stylistic revolution in the megalithic art of the Boyne Valley. Archaeology Ireland 3(4), 138-142.

O’Sullivan, M. 1993a. Megalithic Art in Ireland. Dublin: Country House.

O'Sullivan, M. 1993b. Recent investigations at Knockroe passage tomb. Journal of Royal Society of Antiquaries of Ireland 123, 5-8.

O’Sullivan, M. 1995. The east tomb at Knockroe. Old Kilkenny Review 47, 11-30.

O'Sullivan, M. 1996a. Megalithic art in Ireland and Brittany: divergence or convergence? Revue Archéologique de l'Ouest, supplément 8, 81-96.

O'Sullivan, M. 1996b. Comment on 'Entering alternative realities: cognition, art and architecture in Irish Passage Tombs’ by J. Dronfield. Cambridge Archaeological Journal 6(1), 59.

O’Sullivan, M. 1996c. A platform to the past - Knockroe passage tomb. Archaeology Ireland 10(2), 11-13.

O'Sullivan, M. 1997. On the meaning of megalithic art. Brigantium 10, 23-35.

O’Sullivan, M. 2004. Little and large: comparing Knockroe with Knowth. In H. Roche, E. Grogan, J. Bradley, J. Coles and B. Raftery (eds), From Megaliths to Metals: essasys in honour of George Eogan, 44-50. Oxford: Oxbow Books.

O'Sullivan, M. 2005. Duma na nGiall: the Mound of the Hostages, Tara. Bray: Wordwell.

O'Sullivan, M. 2006. The Mound of the Hostages, Tara: a pivotal monument in a ceremonial landscape. Archaeology Ireland. Heritage Guide 32.

Renfrew, C. 2003. Figuring it out. What are we? Where do we come from? The parallel visions of artists and archaeologists. London: Thames \& Hudson.

Robin, G. 2010. Spatial structures and symbolic systems in Irish and British passage tombs: the organization of architectural elements, parietal carved signs and funerary deposits. Cambridge Archaeological Journal 20(3), 373-418.

Rose, M. 2010. Envisioning the future: ontology, time and the politics of non-representation. In B. Anderson and P. Harrison (eds), Taking Place: non-representational theories and geography, 341-61. Farnham: Ashgate Publishing.

Rotherham, E. C. 1895. On the excavation of a cairn on Slieve-na-Caillighe, Loughcrew. Journal of the Royal Society of Antiquaries of Ireland 25(3), 311-6. 
Russell, I. 2011. Art and archaeology. A modern allegory. Archaeological Dialogues 18 (2) 172-76.

Sagmeister, R. 2005. 'Sex' and 'Death': the body as battlefield between heaven and hell. In E. Schneider (ed.), Jake and Dinos Chapman: Hell. Sixty-Five Million Years BC. Sex Death Insult to Injury. The Chapman Family Collection. Bregenz: Kunsthaus Bregen\%:

Self, W. 2006. Art for fiction's sake. Tate etc. 8, 84-5.

Shanks, M. and Witmore, C. 2009. Memory practices and the archaeological imagination in risk society: design and long term community. Available at: http://documents.stanford.edu/ michaelshanks /438?view=print Accessed: 20 February 2010.

Shanks, M. and Witmore, C. 2010. Memory practices and the archaeological imagination in Risk Society: design and long term community. In S. Koerner and I. Russell (eds), The Unquiet Past, 269-89. Aldershot: Ashgate Publishing.

Sheridan, J. A. 1985/1986. Megaliths and megalomania: an account, and interpretation, of the development of passage tombs in Ireland. Journal of Irish Archaeology 3, 17-30.

Sloterdijk, P. 2005. Forward to the theory of spheres. In M. Ohanian and J. C. Royoux (eds), Cosmographs, 223-41. New York: Lukas and Sternberg.

Storr, R. 2003. Franz West's corporeal comedy. Art in America 91(10), 96-99.

Stout, G. and Stout. M. 2008. Newgrange. Cork: Cork University Press.

Thomas, J. 1992. Monuments, movement and the context of megalithic art. In N. Sharples and A. Sheridan (eds), Vessels for the Ancestors, 143-55. Edinburgh: Edinburgh University.

Thomas, J. 2004. Archaeology and Modernity. London: Routledge.

Tilley, C. 1991. Material Culture and Text: the art of ambiguity. London: Routledge.

Tringham, R. 2005. Weaving house life and death into places: a blueprint for a hypermedia narrative. In D. Bailey, A. Whittle and V. Cummings (eds), (Un)settling the Neolithic, 98-111. Oxford: Oxbow Books.

Van Saaze, V. 2009. Doing artworks. An ethnographic account of the acquisition and conservation of No Ghost just Shell. Krisis: Journal for Contemporary Philosopby 1, 20-32.

Verwoert, J. 2003. Adaptation: Franz West. Frieze 76, 98-101.

Wilde, W. 1849. The Beauties of the Boyne and the Blackwater. Reprinted [2003]. County Galway: Kevin Duffey. 